\title{
Psychological trauma and moral injury in religious leaders during COVID-19
}

\section{Greene, T., Bloomfield, M. and Billings, J}

\begin{abstract}
Religious leaders are at risk of psychological trauma and moral injury during the COVID-19 pandemic. This article highlights potentially traumatic or morally injurious experiences for religious leaders, and provides evidence-based recommendations for mitigating their impact.
\end{abstract}

\section{Manuscript}

Since the outbreak of the COVID-19 pandemic, considerable media and academic attention has been directed towards the mental health impact on various high-risk groups, particularly 'frontline' workers - those that are key to the treatment of individuals with COVID-19 (Chen et al., 2020; Lai et al., 2020). Another group of 'frontline' workers at high risk of psychological distress, but which have largely been overlooked, are religious leaders of faithbased communities. While they are not involved in the medical care of people, they play a key role in supporting individuals, families and communities in coping with the pandemic, and especially so for those that are ill or bereaved by COVID-19. Due to the implementation of quarantine and other social distancing measures, there has been a huge shift in the daily work practices of religious leaders, some of which increase the risk of negative mental health outcomes (Lewis et al., 2007), and in particular for moral injury.

Being part of a faith-based community can be a protective factor for mental health following disasters and crises (Milstein, 2019). This is partly due to the sense of belonging and the emotional and material support derived from being part of a community. It is clear, however, that religious leaders are key, as community members may turn to them for comfort and 
advice in getting through difficult times. While this role can be deeply rewarding, it also comes with risks.

Previous studies have highlighted the risk of burnout in religious leaders, noting that they tend to not prioritise self-care, and often experience work overload, emotional isolation, and like they are permanently 'on call' (Jackson-Jordan, 2013). Furthermore, religious leaders can suffer distress as result of their exposure to other people's traumatic experiences, often referred to as secondary or vicarious trauma (Hendron et al., 2014). These negative mental health outcomes are likely to occur more frequently during the COVID-19 pandemic, and may be compounded by the fact that religious leaders and their community have a shared experience of the trauma stressor. In some respects this may be helpful, but it also poses risks as religious leaders have to actively cope with their own experiences while also helping others (Baum, 2014).

One area that has not yet been addressed in the academic literature, but may be particularly relevant in the COVID-19 pandemic, is that of moral injury in religious leaders. Moral injury has been defined as the psychological distress caused by actions, or their omission, which violate an individual's moral code (Litz et al., 2009). While moral injury is not in itself a mental disorder, it has been associated with a range of mental health problems, including PTSD, depression, anxiety and suicidality (Griffin et al., 2019; Williamson et al., 2018). Moral injury has generally been studied in the context of military experiences, although there are studies of moral injury in other occupational groups, such as teachers, journalists and healthcare workers (Griffin et al., 2019; Williamson et al., 2020; Williamson et al., 2018), there has not yet been any focus on religious leaders.

Potentially morally injurious events (PMIEs) refer to acts that an individual has done or failed to do (transgressions of self) (Nash et al., 2013), or has observed other people do or fail to do 
(transgressions of others). Additionally, people may feel that they have been betrayed by those in positions of authority, or even a sense of theological challenge (Fontana \& Rosenheck, 2004; Koenig et al., 2019). In the following we highlight some PMIEs for religious leaders that may arise during the COVID-19 pandemic.

Due to restrictions implemented in many countries, religious leaders are not able to conduct in-person meetings, make hospital or home visits, and are prohibited from gathering their communities together. In addition, religious leaders are not able to conduct weddings, christenings, and many other joyful lifecycle events, which may feel like a loss and give a sense of 'imbalance' in the work they are doing. While the public health reasons for doing so are clear, religious leaders may find themselves struggling with not being able to provide support and comfort to their congregation in the ways that they are accustomed, and feel distressed by this 'act of omission'. In other words, failing to do what they feel morally obliged to do, which may feel like a transgression of self.

Another area which is likely to be particularly problematic is around death and mourning. The normal rituals that religious leaders perform are being interfered with. Religious leaders are prohibited from visiting those dying from COVID-19, and providing direct in-person comfort and end-of-life religious rituals. In many countries, mourners at funerals are limited to immediate family (regardless of the cause of death), and sometimes not even that; if any of the mourners have symptoms of COVID-19, they will not be allowed to attend. Open coffin funerals are not allowed for those who died from COVID-19, nor ritual cleaning of the body of the deceased, as undertaken by some religions. Religious leaders may find themselves very conflicted as they have no choice but to follow these instructions, which are both potentially devastating to the mourners and indeed to the religious leaders themselves, and may cause a sense of betrayal; leaders may even believe that they themselves have committed a religious transgression. 


\section{Recommendations}

Given the risks relating to moral injury, and more broadly to burnout, and secondary trauma, what does the literature suggest regarding protective factors? Below are a list of recommendations based on existing knowledge regarding psychological stressors for religious leaders, and also drawing from evidence based on other occupational groups (Billings et al., 2020; Greenberg et al., 2020; Ludick \& Figley, 2017; Williamson et al., 2020; Williamson et al., 2018).

Self care. It is important for religious leaders to attend to self-care. This means taking regular breaks, and trying to schedule time away from professional tasks. Try to eat, drink and sleep properly.

Spirituality. Self-care for religious leaders includes not only physical and mental, but also spiritual aspects. This is an unprecedented situation that may be theologically challenging for some. Setting aside time to focus on spirituality can help with processing this.

Acknowledge moral conflicts. It is important to acknowledge the moral conflicts that will likely emerge. Discussing them with colleagues and being prepared for some of the possible responses may facilitate coping and acceptance of distress.

Purpose. Religious leaders should try to maintain a strong sense of purpose. While it is difficult to do work in conditions that are far from ideal, it plays a critical role in comforting people in difficult times.

Supervision and peer support. Try and implement supervision, mentoring and peer-to-peer support. Religious leaders can often find themselves isolated and depleted by their role. If 
such structures already exist, it is not sufficient just to have them, but vital to actively make use of them.

Social support. Staying in touch with family and friends is a key buffer of distress, and can be a great source of strength.

Professional support. Religious leaders should be aware of the professional support that is available. This can include general psychological support. For some denominational groups there are bespoke counselling services for their leaders. Religious leaders should know how to access this support, and be prepared to do so if needed.

\section{Conclusion}

It is important that religious leaders keep in mind that they are doing important work, but are also living through difficult times along with everyone else. Furthermore, they will experience some stressors unique to their role. Attending to self-care, sharing difficult experiences with colleagues, accepting the likelihood of moral conflict, and getting professional help when needed, can all facilitate coping with the unique challenges brought by the COVID-19 pandemic. 


\section{References}

Baum, N. (2014). Professionals' double exposure in the shared traumatic reality of wartime: Contributions to professional growth and stress. The British Journal of Social Work, 44(8), 2113-2134.

Billings, J., Greene, T., Kember, T., Grey, N., El Leithy, S., Lee, D., Kennerley, H., Albert, I., Robertson, M. D., Brewin, C., \& Bloomfield, M. (2020). Supporting Hospital Staff During COVID-19: Early Interventions. Occupational Medicine. https://doi.org/https://doi.org/10.1093/occmed/kqaa098

Chen, Q., Liang, M., Li, Y., Guo, J., Fei, D., Wang, L., He, L., Sheng, C., Cai, Y., \& Li, X. (2020). Mental health care for medical staff in China during the COVID-19 outbreak. The Lancet Psychiatry, 7(4), e15-e16.

Fontana, A., \& Rosenheck, R. (2004). Trauma, change in strength of religious faith, and mental health service use among veterans treated for PTSD. The Journal of nervous and mental disease, 192(9), 579-584.

Greenberg, N., Docherty, M., Gnanapragasam, S., \& Wessely, S. (2020). Managing mental health challenges faced by healthcare workers during covid-19 pandemic. BMJ, 368.

Griffin, B. J., Purcell, N., Burkman, K., Litz, B. T., Bryan, C. J., Schmitz, M., Villierme, C., Walsh, J., \& Maguen, S. (2019). Moral injury: An integrative review. Journal of Traumatic Stress, 32(3), 350-362.

Hendron, J. A., Irving, P., \& Taylor, B. J. (2014). Clergy stress through working with trauma: A qualitative study of secondary impact. Journal of Pastoral Care \& Counseling, 68(4), 1-14.

Jackson-Jordan, E. A. (2013). Clergy burnout and resilience: A review of the literature. Journal of Pastoral Care \& Counseling, 67(1), 1-5.

Koenig, H. G., Youssef, N. A., \& Pearce, M. (2019). Assessment of moral injury in veterans and active duty military personnel with PTSD: a review. Frontiers in psychiatry, 10.

Lai, J., Ma, S., Wang, Y., Cai, Z., Hu, J., Wei, N., Wu, J., Du, H., Chen, T., \& Li, R. (2020). Factors Associated With Mental Health Outcomes Among Health Care Workers Exposed to Coronavirus Disease 2019. JAMA Network Open, 3(3), e203976-e203976.

Lewis, C. A., Turton, D. W., \& Francis, L. J. (2007). Clergy work-related psychological health, stress, and burnout: An introduction to this special issue of Mental Health, Religion and Culture. Mental Health, Religion \& Culture, 10(1), 1-8. 
Litz, B. T., Stein, N., Delaney, E., Lebowitz, L., Nash, W. P., Silva, C., \& Maguen, S. (2009). Moral injury and moral repair in war veterans: A preliminary model and intervention strategy. Clinical Psychology Review, 29(8), 695-706.

Ludick, M., \& Figley, C. R. (2017). Toward a mechanism for secondary trauma induction and reduction: Reimagining a theory of secondary traumatic stress. Traumatology, 23(1), 112.

Milstein, G. (2019). Disasters, psychological traumas, and religions: Resiliencies examined. Psychological trauma: theory, research, practice, and policy, 11(6), 559.

Nash, W. P., Marino Carper, T. L., Mills, M. A., Au, T., Goldsmith, A., \& Litz, B. T. (2013). Psychometric evaluation of the moral injury events scale. Military Medicine, 178(6), 646-652.

Williamson, V., Murphy, D., \& Greenberg, N. (2020). COVID-19 and experiences of moral injury in frontline keyworkers. Journal of Occupational Medicine. https://doi.org/https://doi.org/10.1093/occmed/kqaa052

Williamson, V., Stevelink, S. A., \& Greenberg, N. (2018). Occupational moral injury and mental health: systematic review and meta-analysis. The British Journal of Psychiatry, 212(6), 339346. 